\title{
Acidulation and Regeneration of Bamboo Derived Sorbents for Gas Phase Adsorption of Elemental Mercury
}

\author{
Naved Siddiqui and Jarlen Don* \\ Department of Mechanical Engineering and Energy Processes \\ Southern Illinois University, Carbodnale, IL 62901-6603 \\ *Corresponding Author - Email: jdon@siu.edu. Tel: 618-453-7004
}

\begin{abstract}
This paper presents results that illustrate the recycling of a bamboo derived sorbent used for the capture of elemental mercury $\left(\mathrm{Hg}^{0}\right)$. The bamboo derived sorbent used is essentially a $\mathrm{HCl}$ functionalized activated carbon prepared from carbonization and $\mathrm{CO}_{2}$ activation of raw bamboo, that could potentially provide an alternative way to existing methods in removing mercury from flue gases from coal-fired plants. In this study, the bamboo derived sorbents were tested in a batch test using a mercury permeation tube as the source and nitrogen as a carrier gas. The recycling or regeneration of an activated carbon is an important issue to address from a coal-fired power plant point of view, and an attempt has been made to test the behavior of bamboo derived sorbents with various treatments including carbonized, carbonized-activated, carbonized-activated-acidulated, and then a follow-up recycled run after sample treatments in gas phase. From the study, it was found that bamboo derived activated carbon can be successfully acidulated using various normalities of $\mathrm{HCl}$ where weak solutions can be very effective in functionalizing the surface of the sorbent and capturing mercury. In order to recycle and reuse bamboo derived sorbents, stronger normalities of $\mathrm{HCl}$ would be desired.
\end{abstract}

Keywords: Bamboo, Activated Carbon, Mercury, Hydrochloric Acid, Acidulation, Regeneration

\section{INTRODUCTION}

Mercury is a hazardous pollutant present in flue gases fired from coal fired power plants. The toxic effects of mercury are known to cause health concerns in humans through bioaccumulation in the food chain via fish, and also affect other mammals. The US EPA continuously works on developing protocols on the capping of mercury emissions [1]. 
Activated carbons have been reported as sorbent materials numerous times for the capture of elemental mercury $\left(\mathrm{Hg}^{0}\right)$, which is more difficult to remove than oxidized $\left(\mathrm{Hg}^{2+}\right)$ and particulate mercury $\left(\mathrm{Hg}_{\mathrm{p}}\right)$ in coal fired plants upstream of particulate control devices including baghouses or electrostatic precipitators (ESP's) [2, 3, 7]. However, capture of elemental mercury using conventional methods remains elusive due to its low melting point, high vapor pressure, and low solubility in water [3]. Powdered activated carbon injection technology provides very short residence times, mass transfer limitations, and requires a large $\mathrm{C} / \mathrm{Hg}$ ratio. Therefore, there remains a search for a viable technology for capture of elemental mercury in flue gases of coalfired plants $[3,4]$.

Apart from studies conducted on mercury adsorption using charcoal based products such as unburned carbon [5,6], various studies have been conducted for the production of activated carbons from agricultural by products as reported by [7] such as palm-tree cobs, plum kernels, cassava peel, bagasse, jute fiber, rice husks, olive stones, date pits, fruit stones and nutshells. Bamboo derived activated carbon has been reported as a potential adsorbent several times $[7,8]$ in aqueous forms. Bamboo, being a material with low sulfur, nitrogen and ash content, and high carbon and oxygen content [10] makes it a very viable material for developing a sorbent for capture of mercury. Also, owing to its high structural integrity, and high growth rate of $30 \%$ regeneration in a year $[9,10]$ make it an attractive choice of using it as a source of activated carbon for adsorption of elemental mercury. Bamboo shows a highly oriented cellular structure, which is a very important property for adsorption characteristics. It belongs to the sub-family Bambusoidae of the family Poaceae (Gramine), which falls under the grass family, and has a typical xylem tissue structure $[8,11]$.

The first step in order to derive the activated carbon from bamboo is to carbonize it in an inert atmosphere such as nitrogen at temperatures under $1000^{\circ} \mathrm{C}[10,12]$, which vaporizes the protoxylem and metaxylem in the bamboo forming large macropores. The carbonizing temperature determines the pore size and surface area of the carbonized bamboo, which according to [12] falls around $490.8 \mathrm{~m}^{2} \mathrm{~g}^{-1}$ for bamboo charred at $1000^{\circ} \mathrm{C}$. Further, the activation process is where the surface porosities are increased, and a large proportion of the xylem is gasified, enlarging the pores, which improves the adsorbing capacity of the carbon. Various methods have been reported for the activation including steaming, where relatively large surface areas have been reported of up to $1038 \mathrm{~m}^{2} \mathrm{~g}^{-1}$ [8], chemical methods, and also using $\mathrm{CO}_{2}$, with the last method being employed in this study.

It has also been reported that activated carbon can only be regenerated a few times before they exhibit unacceptably low activity for mercury removal. It is thought that the mercury removal from a flue gas stream takes place due to a surface functional group (SFG) on the activated carbon. In previous studies, activated carbon was treated with halogens or chalcogens such as Chlorine, Bromine, Iodine and Sulfur which improved the $\mathrm{Hg}$ adsorption, and functionalized 
with $\mathrm{O}, \mathrm{CO}$, or $\mathrm{OH}$, or leached with $\mathrm{HF}$ to enhance the removal of organic substances in liquids $[13,14,15,16]$. Also, impregnating virgin Powdered Activated Carbon (PAC) with $\mathrm{Cl}$ or $\mathrm{S}$ increased the $\mathrm{Hg}$ capacity by a few hundred times, e.g., up to $4 \mathrm{mg} / \mathrm{g}$ for $\mathrm{Hg}^{0}$ and $\mathrm{HgCl}_{2}$ as compared to virgin carbons which had a capacity ranging from $5-50 \mu \mathrm{g} / \mathrm{g}[14,15]$. Therefore, chlorine is one such functional group which can be used to functionalize the bamboo derived activated carbon using $\mathrm{HCl}$, as it can improve the $\mathrm{Hg}^{0}$ removal capacity by 300 times as compared to virgin activated carbons $[13,17]$. This would also enable the reduction of mineral matter content that would also bring about changes in the surface area and pore texture of the sorbent, since the mineral matter can block a part of the carbon porosity [18]. It is also feasible that this $\mathrm{HCl}$ impregnation might be able to recycle or regenerate the activated carbon after it captures the mercury. Other studies have also been conducted where bamboo derived carbon was treated with dilute sulfuric acid for the capture of ammonia in aqueous solutions [19], therefore there is a thought that $\mathrm{HCl}$ impregnation could help in functionalizing the surface of bamboo derived sorbents in order to capture mercury in gas phase.

The work presented in this study reports a study on activated carbon derived from bamboo in solid form, which have been further functionalized using various normalities of $\mathrm{HCl}$. The performance of elemental mercury uptake under batch tests has been studied. Further batch tests have been conducted on previously used samples, which have again been regenerated using $\mathrm{HCl}$, and tests have been run again.

\section{MATERIALS \& METHODS}

\subsection{Preparation of Bamboo Derived Sorbents}

The first step was to prepare the bamboo derived sorbents, which was done using a series of steps. Raw bamboo slats were acquired from Cali Bamboo and cut into strips of approximately $17.5 \mathrm{~cm} \times 2.2 \mathrm{~cm} \times 0.3 \mathrm{~cm}$ in dimensions. In some strips, the outer bark of the bamboo, known as the epidermal tissue was maintained (skin or bark), while in other cases it was shaved off (noskin or no-bark).

This raw material was then processed to develop the bamboo derived sorbent. The first step to prepare any variety of sorbent was carbonization, which was done in order to convert raw bamboo into bamboo charcoal. This process was carried out in a box furnace (CM Rapid Temp Furnace - 1704 series) under continuous flowing nitrogen. The carbonization cycle consisted of a drying time at $200^{\circ} \mathrm{C}$ for an hour in order to take the moisture out from the bamboo. The samples were then ramped to $800^{\circ} \mathrm{C}$ at $5^{\circ} \mathrm{C} / \mathrm{min}$, and then held for 2 hours. The temperature was then allowed to drop naturally. The bamboo strips tended to shrink and bend, and therefore a dead weight was placed on top of the samples to retain the flatness. 
The carbonized samples were then activated in order to obtain a larger surface area. This process was performed in the box CM Rapid Temp furnace under flowing $\mathrm{CO}_{2}$. They were ramped to $500^{\circ} \mathrm{C}$ at about $4.2^{\circ} \mathrm{C} / \mathrm{min}$, and held for 2 hours with a continuous flow at $150 \mathrm{sccm}$. The temperature was allowed to drop naturally. Application of dead weight was not necessary.

The activated samples were acidulated using $\mathrm{HCl}$ solutions of various normalities, and allowed to be treated for approximately 3-5 days. This was done on cut samples with desired weights, which was approximately kept at 0.03 grams. These cut samples were washed in about $20 \mathrm{ml}$ distilled water 3 times, and then dried in an oven overnight. Three different $\mathrm{HCl}$ solutions were used for acidulation $-0.05 \mathrm{~N} \mathrm{HCl}, 0.1 \mathrm{~N} \mathrm{HCl}$ and $1 \mathrm{~N} \mathrm{HCl}$.

In order to recycle or regenerate the samples after adsorption tests were done, a similar procedure was repeated for the Recycling. The $0.1 \mathrm{~N} \mathrm{HCl}$ and $0.05 \mathrm{~N} \mathrm{HCl}$ samples were recycled using a $0.2 \mathrm{~N} \mathrm{HCl}$ solution, and the $1 \mathrm{~N} \mathrm{HCl}$ samples were recycled using a $1 \mathrm{~N} \mathrm{HCl}$ solution. These samples were tested under the Batch Test for mercury adsorption.

The surfaces of the developed sorbent materials were characterized through Scanning Electron Microscopy using a Hitachi S570 scanning electron microscope.

\subsection{Experimental Setup}

In order to evaluate the mercury adsorption performance of various prepared sorbents, they were subject to Batch Tests. A schematic of the batch test is shown in Figure 1. Elemental mercury was permeated from a standard mercury permeation tube, acquired from VICI Metronics, which was placed in one section of a glass U-tube. The other section of the U-tube was filled with glass beads. This U-tube was placed in a temperature controlled bath of Corn oil, which was done in a Cole-Parmer - Microprocessor Controlled Water Bath, while using corn oil as the heating medium due to its high flash point. The amount of mercury permeated depended on the temperature of the hot bath and the flow rate of nitrogen through the permeation tube. Transferlines, which were primarily Teflon tubing led the gas through the permeation tube into sampling bags, which were acquired from SKC - 231 Series. Two sampling bags were employed, one of which was used as the main sorption chamber ( $10 \mathrm{~L}$ capacity), where the sorbent material was tested, and the other was used as a calibration bag (5L capacity) in order to ensure that the amount of mercury being permeated was correct as desired. The outlet of the sampling bag was connected to the Jerome J405 Mercury Vapor Analyzer, which measured the concentration of mercury contained in the gas in the sampling bag at any given time.

The sorbent was loaded into the sampling bag using the small opening in the SKC sampling bag, and then sealed. Prior to each test, the system was flushed with nitrogen at least 3 times in order to make sure there was no oxygen in the system. Once this was done, sorbent material was 
sectioned off using clamps and isolated in a corner of the sampling bag, and then the mercury containing nitrogen gas was permeated. Immediately after the gas fill up, the initial concentration of mercury $\mathrm{C}_{0}$ was measured, and then the sorbent material was exposed to the mercury containing gas. Kinetic data of mercury concentration over various intervals of time was then collected.

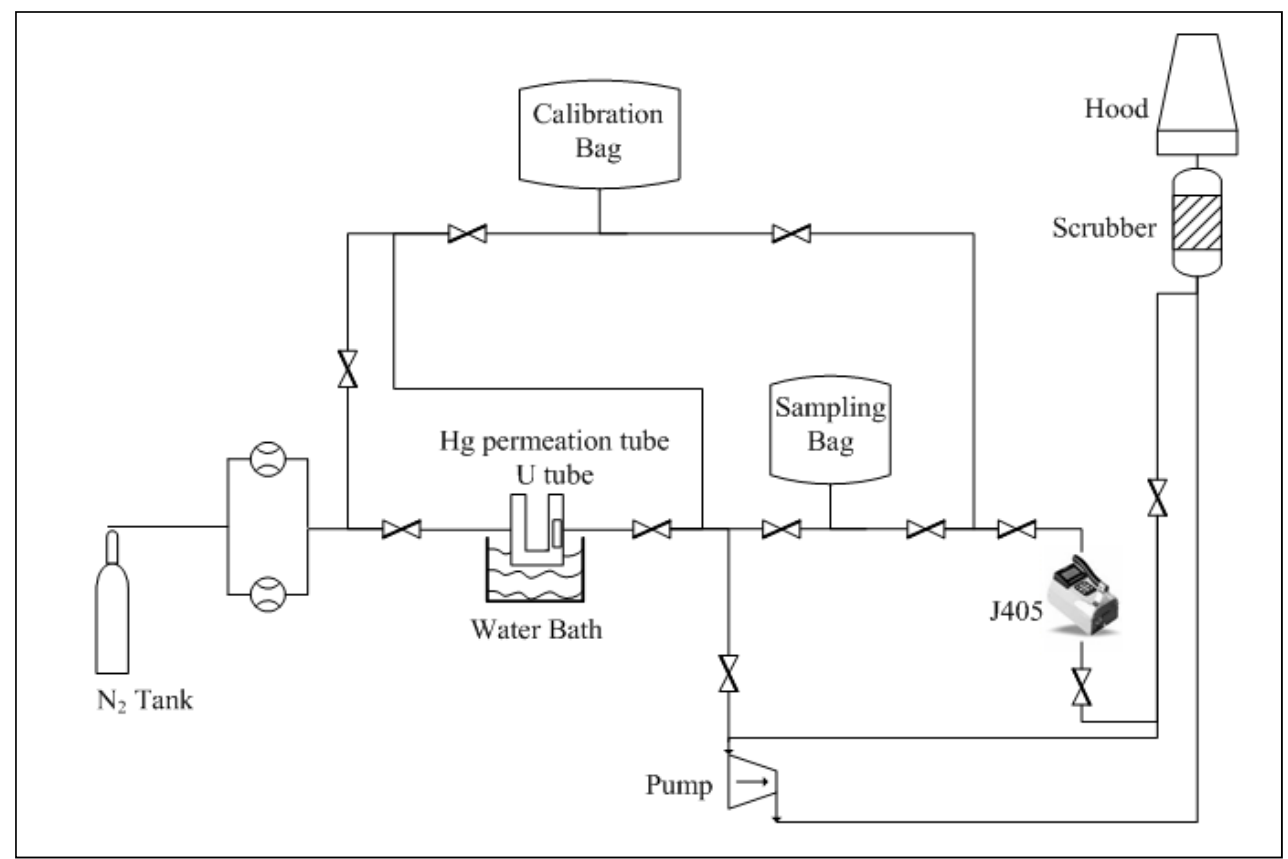

Figure 1: Experimental Setup Schematic

\subsection{Adsorption Studies}

The amount of mercury adsorbed by the bamboo derived sorbent at any time $t$ is represented by $\mathrm{q}_{\mathrm{t}}\left(\mu \mathrm{g} \mathrm{g}^{-1}\right)$, as shown by in equation 1 [7], where $C_{0}$ and $C_{t}\left(\mu \mathrm{g} \mathrm{m}^{-3}\right)$ are the initial concentration and concentration at any time $\mathrm{t}$ of the elemental mercury contained in the gas, $\mathrm{V}$ is the Volume $\left(\mathrm{m}^{3}\right)$ of the gas filled inside the bag, and $\mathrm{m}$ is the mass of the sample loaded $(\mathrm{g})$.

$q_{t}=\frac{\left(C_{0}-C_{t}\right)}{m} V$

Any time the gas containing mercury was sampled, the Jerome J405X drew $120 \mathrm{~cm}^{3}$ of gas, and therefore, the sorbent loading $m_{s}=m / V\left(\mathrm{~g} \mathrm{~m}^{-3}\right)$, changed after each sampling. Therefore, this change in volume at after each sampling was taken into account, and the uptake at each instance was corrected to find the true instantaneous uptake of mercury using the sorbent loading at the time, and finally accumulated to plot uptake curves against time. 
First order Kinetics

A first order rate equation, developed by Lagergren and reported in many adsorption studies including [20] is described in equation 2 as:

$\frac{d q}{d t}=k_{1}\left(q_{e}-q_{t}\right)$

where, $\mathrm{q}_{\mathrm{e}}$ and $\mathrm{q}_{\mathrm{t}}(\mu \mathrm{g} / \mathrm{g})$ describe the adsorption or uptake of elemental mercury by the bamboo derived sorbent at equilibrium and at any time $\mathrm{t}$ respectively. $\mathrm{k}_{1}$ describes the overall rate constant of adsorption using the bamboo derived sorbent.

Upon integrating and applying the boundary conditions, $t=0$ and $q_{t}=0$, to $t=t$ and $q_{t}=q_{t}$, we arrive at

$\ln \left(q_{e}-q_{t}\right)=\ln q_{e}-k_{1} t$

which can be simplified as

$q_{t}=q_{e}\left(1-e^{-k_{1} t}\right)$

Now, if we define a term $\mathrm{q}_{\mathrm{m}}$ as the maximum uptake of mercury assuming all mercury is adsorbed by the bamboo derived sorbent, then we equation 1 becomes:

$q_{m}=\frac{C_{0}}{m_{s}}$

Dividing equation 1 by equation 4 , we can define a term $\alpha_{t}$, which is essentially a dimensionless normalized uptake of mercury $\left(\mu \mathrm{g} \mathrm{m}^{-3} / \mu \mathrm{g} \mathrm{m}^{-3}\right)$ at any time t. This $\alpha_{\mathrm{t}}$, presented in equation 5 reduces to

$\alpha_{t}=\frac{q_{t}}{q_{m}}=\left(1-\frac{C_{t}}{C_{0}}\right)$

Similarly, if we divide equation 4 through by $\mathrm{q}_{\mathrm{m}}$, we arrive at a modified form in equation 7

$\alpha_{t}=\alpha_{e}\left(1-e^{-k_{1} t}\right)$

where $\alpha_{e}=\frac{q_{e}}{q_{m}}$ is the normalized equilibrium uptake of mercury

Therefore, in order to study the adsorption behavior of each bamboo derived sorbent, the normalized uptake of mercury $\alpha_{t}\left(\mu \mathrm{g} \mathrm{m}^{-3} / \mu \mathrm{g} \mathrm{m}^{-3}\right)$ was plotted against time. This behavior was 
curve fitted and smooth lines were plotted corresponding to experimental values of $\alpha_{t}$ using equation 7, where $\alpha_{e}$ and $\mathrm{k}_{1}$ were estimated by maximizing the coefficient of correlation [21] using the solver plug-in in Microsoft Excel. The coefficient of correlation is presented in equation 8 .

$r^{2}=\frac{\sum\left(\alpha_{c}-\bar{\alpha}_{t}\right)^{2}}{\sum\left(\alpha_{c}-\bar{\alpha}_{t}\right)^{2}+\sum\left(\alpha_{c}-\alpha_{t}\right)^{2}}$

where $r^{2}$ is the coefficient of correlation (\%), $\alpha_{c}$ is the calculated normalized uptake of mercury at any time, $\alpha_{t}$ is the measured experimental uptake of mercury at any time t, and $\bar{\alpha}_{t}$ is the average normalized uptake of mercury by the bamboo derived sorbents at any time $t$.

\subsection{Experimental Run}

Approximately $11 \mathrm{~L}$ of mercury containing gas was filled in the Tedlar sampling bags, and the average sample loading was approximately $0.30 \mathrm{~g} \mathrm{~m}^{-3}$. Once the bag was filled, the initial concentration, which was desired to be $100 \mu \mathrm{g} \mathrm{m}^{-3}$ was immediately measured using the Jerome $J 405 X$, and recorded. Subsequently, the sorbent was exposed to the gas, as the mercury adsorption initiated instantaneously. Kinetic data was collected every few hours to track the adsorption behavior of each sorbents variety. Dynamic curves were plotted and then the data was further processed to study the uptake of mercury using each variety of sorbents.

As mentioned earlier, the sorbent loading changed each time kinetic data was collected, as the Jerome J405X drew $120 \mathrm{~cm}^{3}$ of gas from the sampling bag. In cases where kinetic data was collected over a large period of time, the volume of gas had in fact decreased by over $70 \%$ in some cases. Therefore, it was essential to consider the change in sorbent loading and accumulate mercury uptakes to plot the uptake behavior of mercury against time. In addition, due to the variations in initial concentrations, it was necessary to normalize the uptake curves with a maximum $q_{e}$ of 1.0 in order to effectively study and compare the behavior of various bamboo derived sorbents.

\section{RESULTS \& DISCUSSION}

As mentioned in the Materials and Methods section, two sets of samples were prepared, one with skin, and one without skin. The nomenclature used in this study use the letter ' $S$ ' to denote skin samples, and ' $\mathrm{N}$ ' to denote no-skin samples. The nomenclature follows the treatment performed to prepare the sorbents. The first step involved carbonization of the samples (denoted as SC and $\mathrm{NC}$ ), following which activation was done (SCA and NCA). The samples were then treated using a certain concentration of hydrochloric acid in order to functionalize the surface of the bamboo derived sorbents, and the studies here present carbonized-activated sorbents that were acidulated. Therefore these samples are denoted as SCAH-xN or NCAH-xN, where $\mathrm{x}$ is the normality of the 
hydrochloric acid solution. An attempt was made to regenerate acidulated samples, where after a batch-test; they were retreated with a certain $\mathrm{HCl}$ solution. Therefore, these samples are termed as SCAH-xN-RxN or NCAH-xN-RxN. An analysis of these samples is presented in the following paragraphs.

In general, it was found that each subsequent treatment for the preparation of the bamboo derived sorbent improved the uptake performance of the bamboo derived sorbents, in the increasing order of carbonization, carbonization-activation, carbonization-activation-acidulation. The carbonized-activated-regenerated-acidulated samples were retreated with a certain concentration of hydrochloric acid, and it was desired to match initial performance.

The overall conditions including mass of sorbent loaded (g), initial concentration $\mathrm{C}_{0}$, and overall rate constants are presented in Table 1. These are discussed corresponding to the uptake behavior of each sorbent as presented in the following figures and paragraphs. Based on the adsorption kinetics presented in the previous section, and observing the graphs, we find fairly good fits for mercury uptake using first order kinetics. This can be verified using the coefficient of correlation, which is also provided in Table 1, which gives us an idea of the accuracy of overall fits.

Table 1: Overall results describing the uptake behavior of various bamboo derived sorbents

\begin{tabular}{|l|c|c|c|c|}
\hline & mass $(\mathrm{g})$ & $\mathrm{C}_{0}\left(\mu \mathrm{g} \mathrm{m}^{-3}\right)$ & $\mathrm{k}_{1}\left(\mathrm{~h}^{-1}\right)$ & $\mathrm{R}^{2}$ \\
\hline \multicolumn{1}{|c|}{ Skin Samples } & & & & \\
\hline SC & 0.0278 & 103.97 & 0.0072 & 0.9750 \\
\hline SCA & 0.0277 & 98.30 & 0.0224 & 0.9955 \\
\hline SCAH1N & 0.0277 & 96.97 & 0.0365 & 0.9980 \\
\hline SCAH1N-R1N & 0.0276 & 94.67 & 0.0329 & 0.9983 \\
\hline No Skin Samples & & & & \\
\hline NC & 0.0278 & 93.00 & 0.0053 & 0.9946 \\
\hline NCA & 0.0270 & 122.30 & 0.0178 & 0.9618 \\
\hline NCAH0.05N & 0.0272 & 116.05 & 0.0477 & 0.9908 \\
\hline NCAH0.05N - R0.2N & 0.0262 & 96.17 & 0.0245 & 0.9993 \\
\hline NCAH0.1N & 0.0274 & 110.60 & 0.0489 & 0.9903 \\
\hline NCAH0.1N - R0.2N & 0.0267 & 108.00 & 0.0224 & 0.9976 \\
\hline NCAH1N & 0.0283 & 98.62 & 0.0557 & 0.9996 \\
\hline NCAH1N-R1N & 0.0279 & 94.08 & 0.0859 & 0.9868 \\
\hline
\end{tabular}

Figure 2 primarily presents the uptake of mercury using sorbents of various treatments where the epidermal tissue was kept intact. It can clearly be seen from these curves that the adsorption performance of the bamboo derived sorbents improved considerable with each subsequent performance. The overall rate constants of the Skin-Carbonized was found to be $0.0072 \mathrm{~h}^{-1}$. 
Upon activation of the skin sample, the overall rate was improved by $211 \%$ where it was found to be $0.0244 \mathrm{~h}^{-1}$. Also shown in Figure 2, acidulation using $1 \mathrm{~N} \mathrm{HCl}$ improved the overall rate constant by $63 \%$ from the activated sample, which essentially means that using the $1 \mathrm{~N}$ acidulated sample, the mercury contained in the bag (approximately $100 \mu \mathrm{g} \mathrm{m}^{-3}$ ) could be adsorbed to nondetectable levels in about 28 hours, as opposed to 139 hours using the carbonized sample.

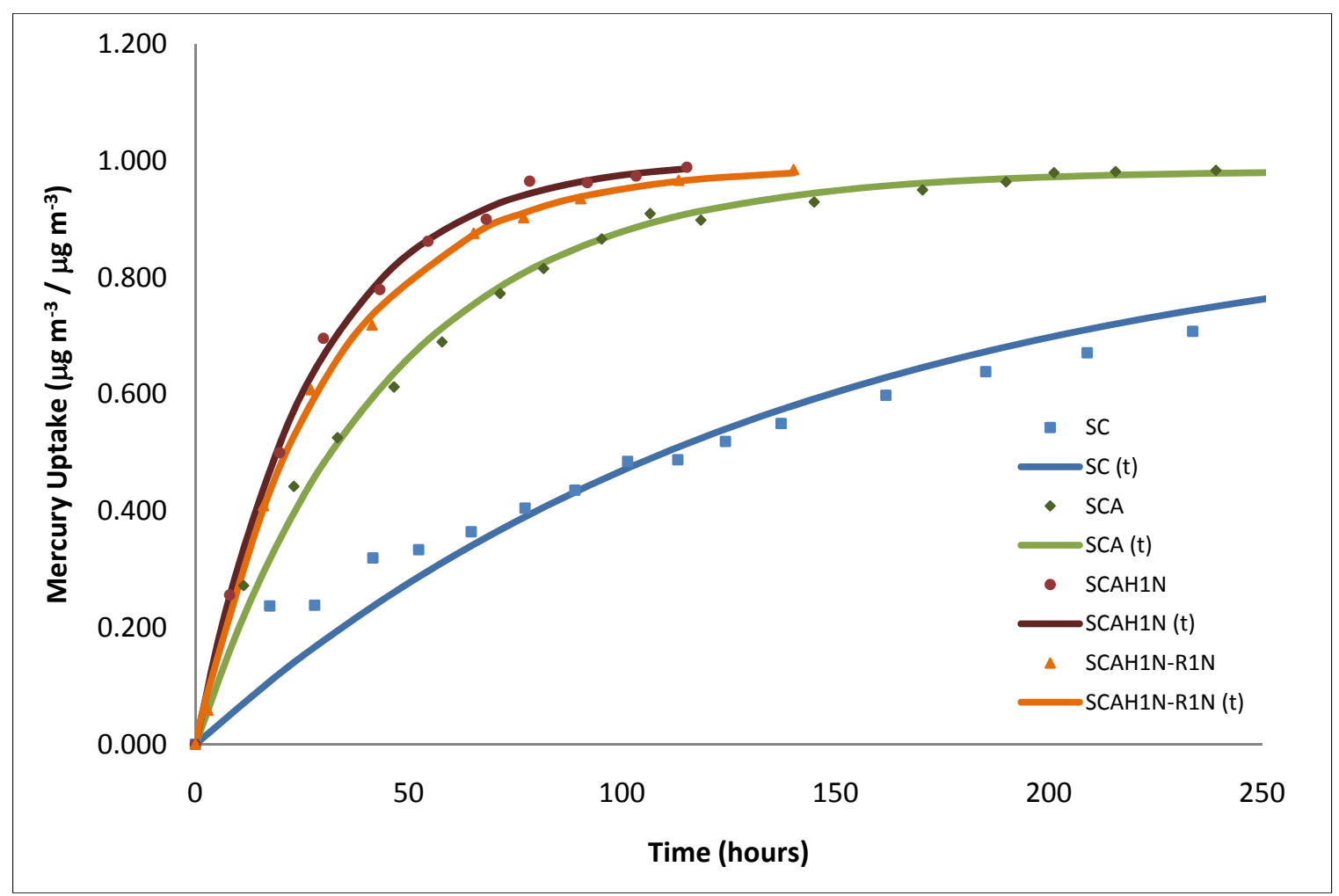

Figure 2: Mercury Uptake performance of bamboo derived sorbents with epidermal tissue with various treatments

Similarly, the findings for no-skin samples presented in Figure 3 also depict a similar pattern, where the overall rate constant of the carbonized samples are found to be $0.0053 \mathrm{~h}^{-1}$. Activation improves the overall rate constant by $236 \%$, and acidulation using $1 \mathrm{~N} \mathrm{HCl}$ solution is improved by very significantly by $213 \%$ using the overall rate constant, which is $0.0557 \mathrm{~h}^{-1}$.

Upon comparing skin and no-skin counterparts, it is found that with the carbonized samples, the skin sample has a faster rate constants compared to the no-skin counterparts. The main reasoning behind this behavior could be due to the higher initial concentration in the skin sample. This behavior changes using the activated sorbents where the no-skin sample shows an overall rate constant of $0.0244 \mathrm{~h}^{-1}$, as compared to the skin sample, which has a rate constant of $0.0178 \mathrm{~h}^{-1}$. Higher initial concentration could be exaggerating this behavior, but the main reason behind this is the larger pore radius found in the no-skin samples. Acidulation of activated sorbents using $1 \mathrm{~N}$ solution of $\mathrm{HCl}$ clearly shows that the no-skin sorbents are much more strongly functionalized, 
and show far greater adsorption performance with an overall rate constant $52.60 \%$ greater at of $0.0557 \mathrm{~h}^{-1}$ as compared to $0.0365 \mathrm{~h}^{-1}$. A comparison between skin and no-skin sample is also shown in SEM studies following the quantitative discussion.

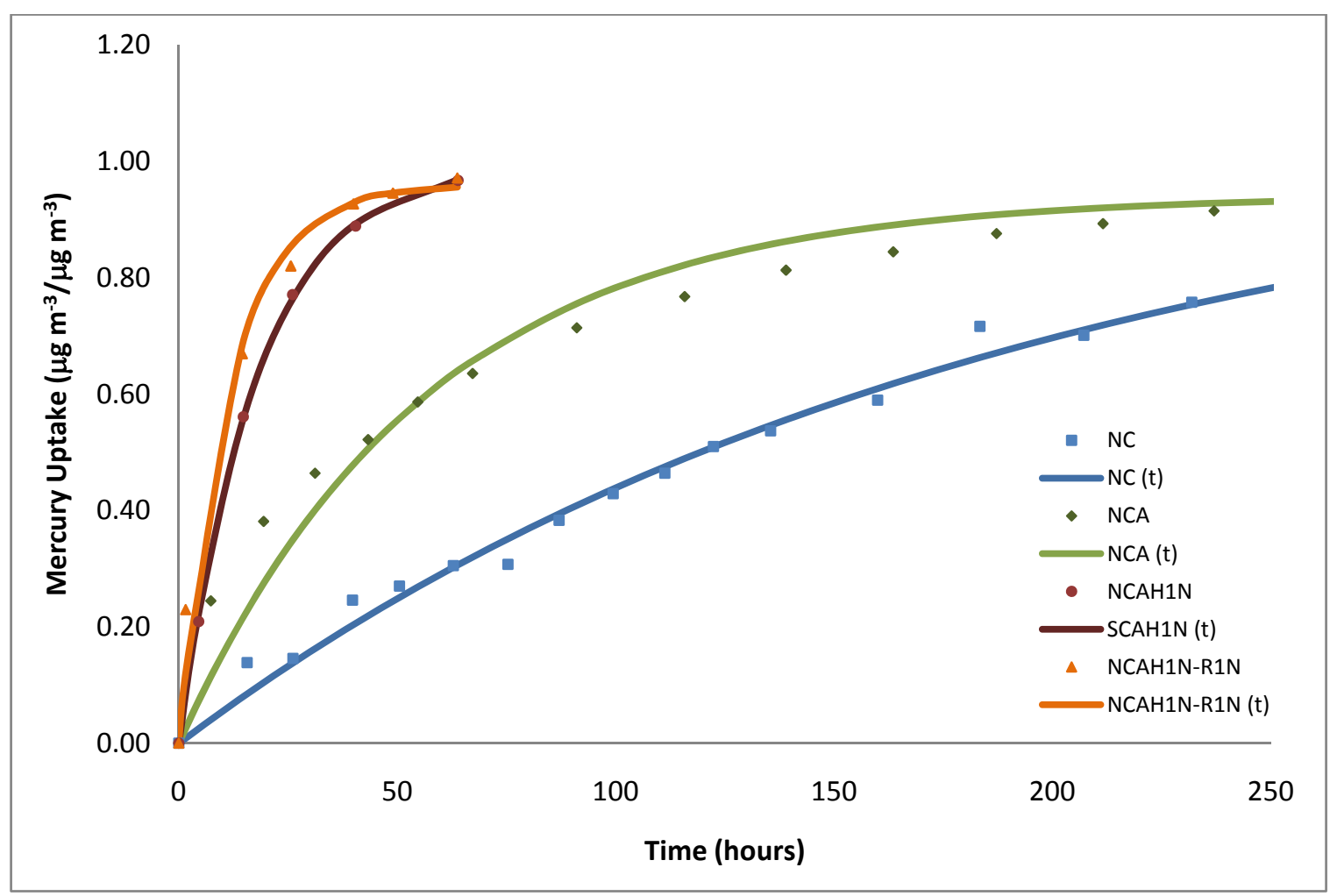

Figure 3: Mercury Uptake performance of bamboo derived sorbents without epidermal tissue with various treatments

As it was determined that acidulation using no-skin samples provided much stronger functionalization on the surface of the bamboo derived sorbents, an effort was made to vary the concentrations of $\mathrm{HCl}$ solutions and study the behavior of mercury uptakes using these samples. $0.05 \mathrm{~N} \mathrm{HCl}$ functionalization improved the performance activated no skin sample by $168 \%$, whereas $0.1 \mathrm{~N} \mathrm{HCl}$ functionalization improved it by $175 \%$, with overall rate constants of 0.0477 and $0.0489 \mu \mathrm{g} \mathrm{g}^{-1} \mathrm{~h}^{-1}$ respectively. The $1 \mathrm{~N} \mathrm{HCl}$ solution improved the performance from activated samples by $213 \%$, which is not drastically different compared to the weaker acidulated solutions. Therefore, even a weak solution of $\mathrm{HCl}$ can be very effective in improving the adsorption performance of the bamboo derived sorbents.

Further, the regeneration of bamboo derived sorbents was addressed. Samples that had undergone a batch test to adsorbed mercury were collected and re-treated using a certain solution of $\mathrm{HCl}$, and tested over. The samples that were originally acidulated using $1 \mathrm{~N}$ solution of $\mathrm{HCl}$ were regenerated using a fresh $1 \mathrm{~N}$ solution of $\mathrm{HCl}$, whereas the samples originally treated using $0.05 \mathrm{~N}$ or $0.1 \mathrm{~N}$ solution of $\mathrm{HCl}$ were regenerated using $0.02 \mathrm{~N}$ solution of $\mathrm{HCl}$. The goal was to 
reproduce the performance of original samples. It can be seen in Figure 4 that neither of the two samples that were regenerated using $0.02 \mathrm{~N}$ solution of $\mathrm{HCl}$ were able to match the performance of original samples. The sample NCAH0.05N having an overall rate constant of $0.0477 \mathrm{~h}^{-1}$ was much faster than regenerated sample, which was labeled as NCAH0.05N-R0.2N and had a rate constant of $0.0245 \mathrm{~h}^{-1}$. In other words, the rate constant had decreased by $48.64 \%$. A similar finding was seen when the $0.1 \mathrm{~N} \mathrm{HCl}$ acidulated sample, labeled as $\mathrm{NCAH} 0.1 \mathrm{~N}$ having an overall rate constant of $0.0489 \mathrm{~h}^{-1}$ was regenerated to NCAH0.1N-R0.2N, which had a rate constant of $0.0245 \mathrm{~h}^{-1}$ implying that this sample was $49.90 \%$ slower. This indicated that the regeneration of a sample needs to be done with a rather stronger solution of $\mathrm{HCl}$.

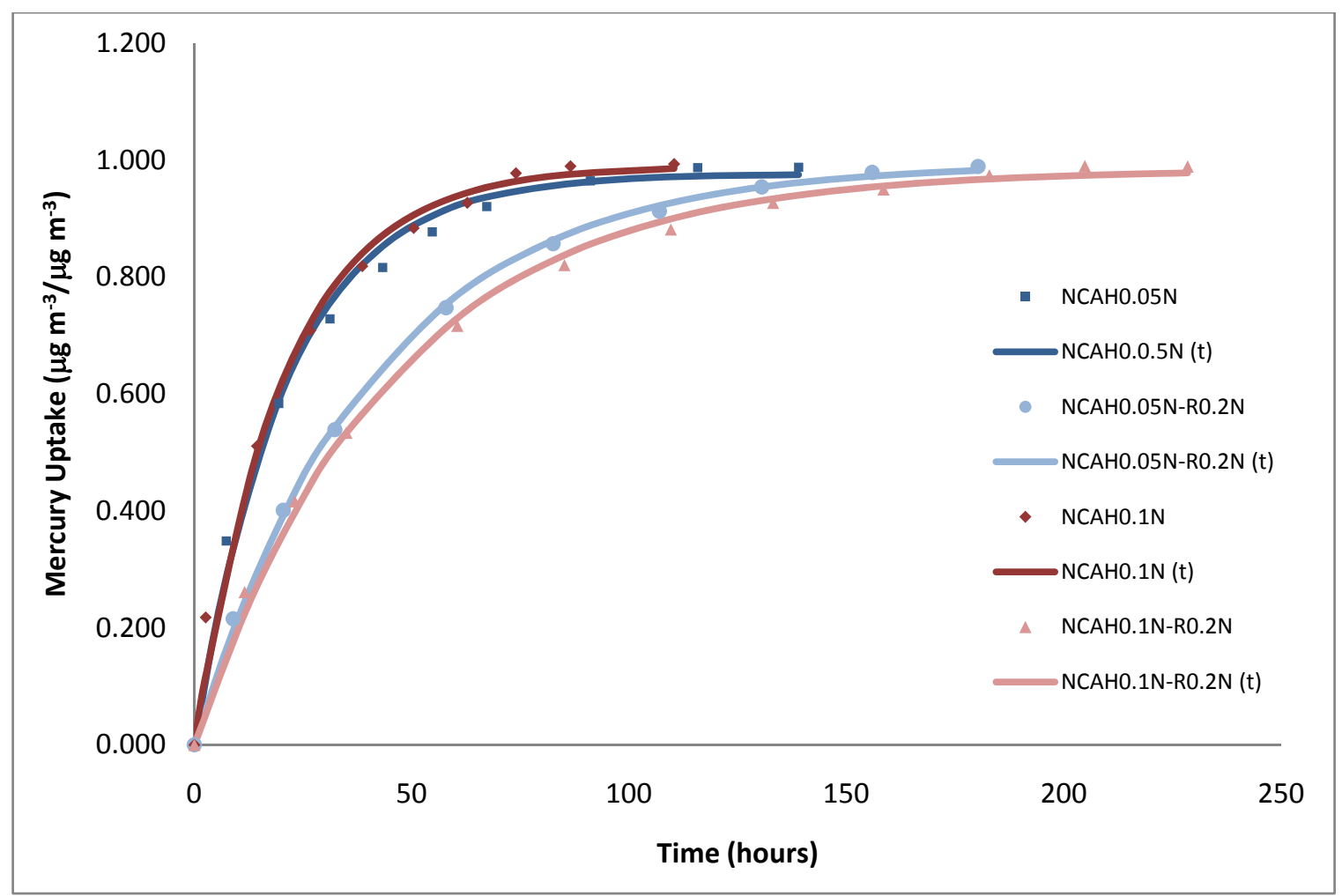

Figure 4: Regeneration of acidulated bamboo derived sorbents without epidermal tissue using low $\mathrm{HCl}$ concentrations

These cases have been shown in Figures 2 and 3, where the $1 \mathrm{~N}$ treated samples SCAH1N and NCAH1N, having overall rate constants of 0.0365 and $0.0557 \mathrm{~h}^{-1}$ respectively were regenerated using a fresh $1 \mathrm{~N}$ solution of $\mathrm{HCl}$. The regenerated sample SCAH1N-R1N had an overall rate constant of $0.0329 \mu \mathrm{g} \mathrm{g}^{-1} \mathrm{~h}^{-1}$, which showed significant regeneration, as the sample was only $9.86 \%$ slower than the original run. The sample NCAH1N-R1N had an overall rate constant of $0.0859 \mu \mathrm{g} \mathrm{g}^{-1} \mathrm{~h}^{-1}$, implying that the mercury adsorption performance of this sample had improved by $54.21 \%$. In fact the initial rate indicates that this is $85.88 \%$ better. This goes on to explain that the bamboo derived sorbents can not only be successfully regenerated using strong acidulations of $\mathrm{HCl}$, but also that there is a strong indication that more vigorous treatment of 
acidulation can drastically improve the adsorption performance of these bamboo derived sorbents, which can be very useful in real life situations in coal-fired plants.

The SEM imaging conducted (Figure 5 and 6) illustrates the difference between bamboo derived sorbents where the epidermal tissue was kept intact (skin) and a sample where the epidermal tissue was removed (no-skin). It can clearly be seen that upon carbonization of the two samples under the same conditions, there is a much greater concentration of the protoxylem and metaxylem in the skin samples as opposed to the no skin samples, which is evidence of gasification of stronger gasification of xylem tissue. The bark material is excellent in providing structural integrity, which is important from a practical standpoint, however, based on performance, the no skin sample, i.e. without the bark material provides more gasified xylem tissues, which lead to micro-porosities through the channels in the bamboo based structure. Similar findings were illustrated when the samples were activated, where the xylem tissue was further gasified, and there is a strong correlation with experimental data, which shows that the NCA samples provides far better adsorption performance as compared to SCA samples.

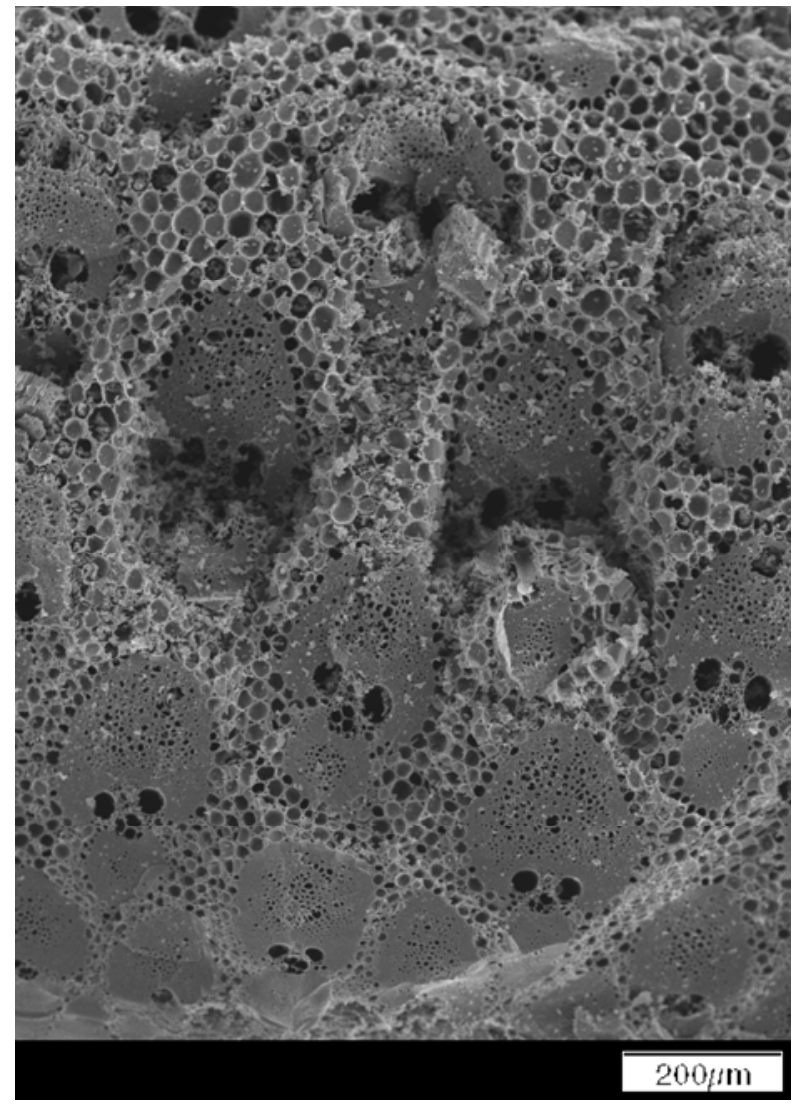

Figure 5: Carbonized-Skin SEM

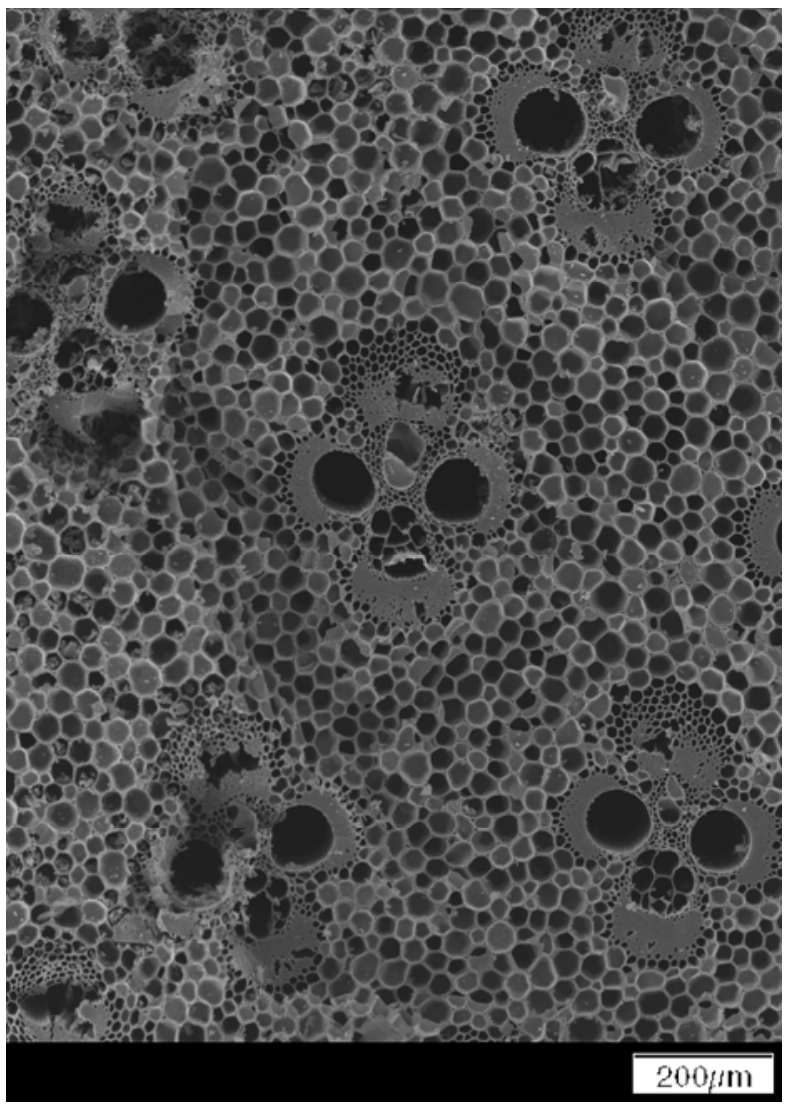

Figure 6: Carbonized-No Skin SEM

As an overall conclusion, which can be illustrated by looking at rate constants in the bar charts provided in Figures 7 and 8, illustrate the improvement in performance of bamboo derived 
sorbents upon each subsequent treatment of carbonization, activation, and further; acidulation. Also addressed was the recycling of $\mathrm{HCl}$ functionalized bamboo derived sorbents. It can be seen that the bamboo derived sorbents that were treated with the weaker $0.1 \mathrm{~N} \mathrm{HCl}$ and $0.05 \mathrm{~N} \mathrm{HCl}$ solutions showed very good mercury uptake performance in original runs. However, when attempted to be recycled using a $0.02 \mathrm{~N} \mathrm{HCl}$ solution, the sorbents did not match original performance. Conversely when the bamboo derived activated carbon was acidulated using $1 \mathrm{~N}$ solution of $\mathrm{HCl}$, and subsequently recycled using a fresh $1 \mathrm{~N}$ solution, not only was the original mercury uptake performance matched, but it was surpassed. This went on to prove the hypothesis that hydrochloric acid treatment is a very effective way of elemental mercury capture in gas phase. Originally, a weak acid solution could be enough to funtionalize the surface of an activated bamboo derived sorbent for enhanced mercury capture, which could be regenerated using a stronger than original treatment solution. This could be a very effective way of retrofitting an effective material in flue streams of coal fired plants for mercury capture.

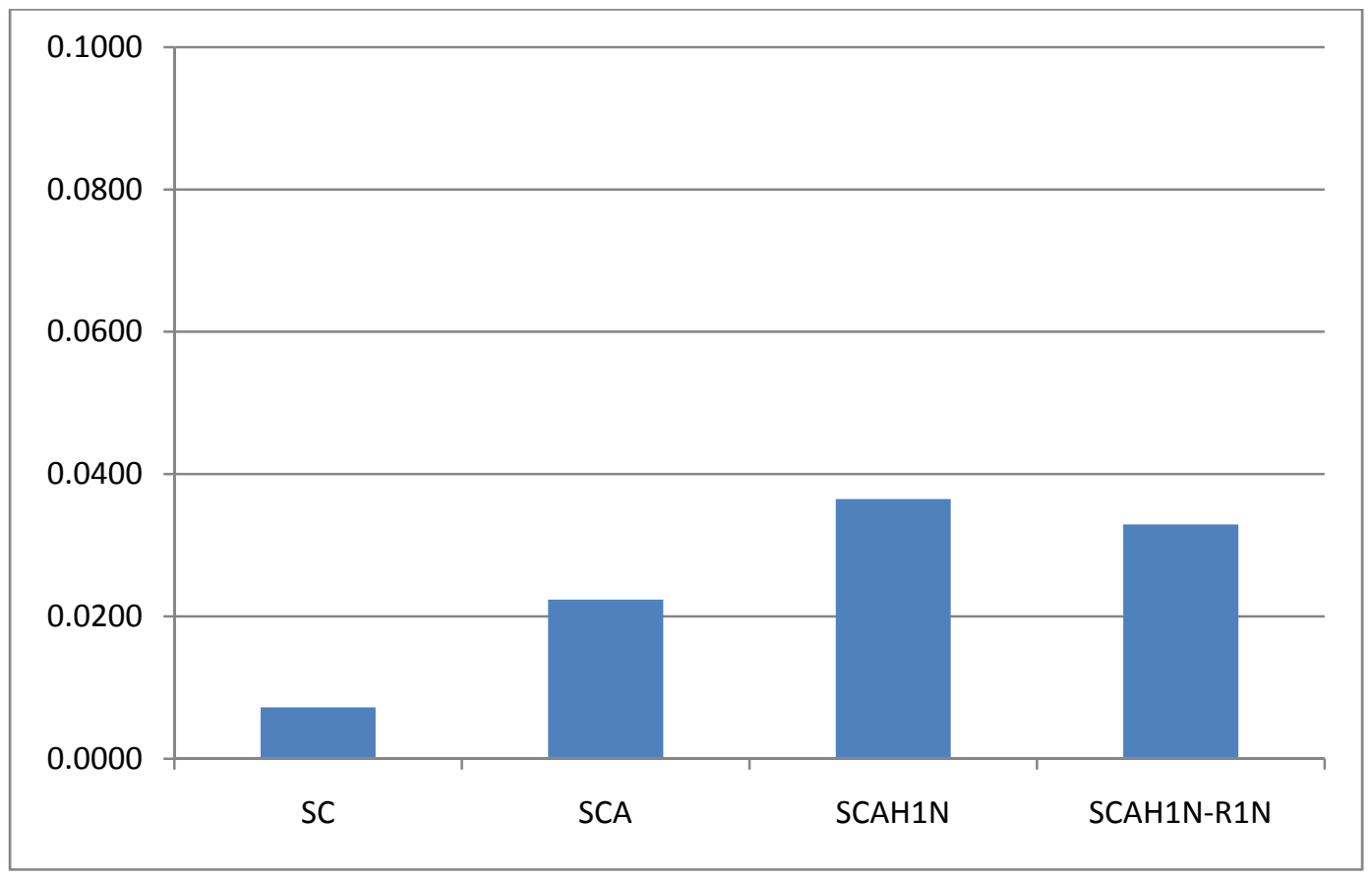

Figure 7: Rate Constants for mercury uptake by bamboo derived sorbents with skin with various treatments 


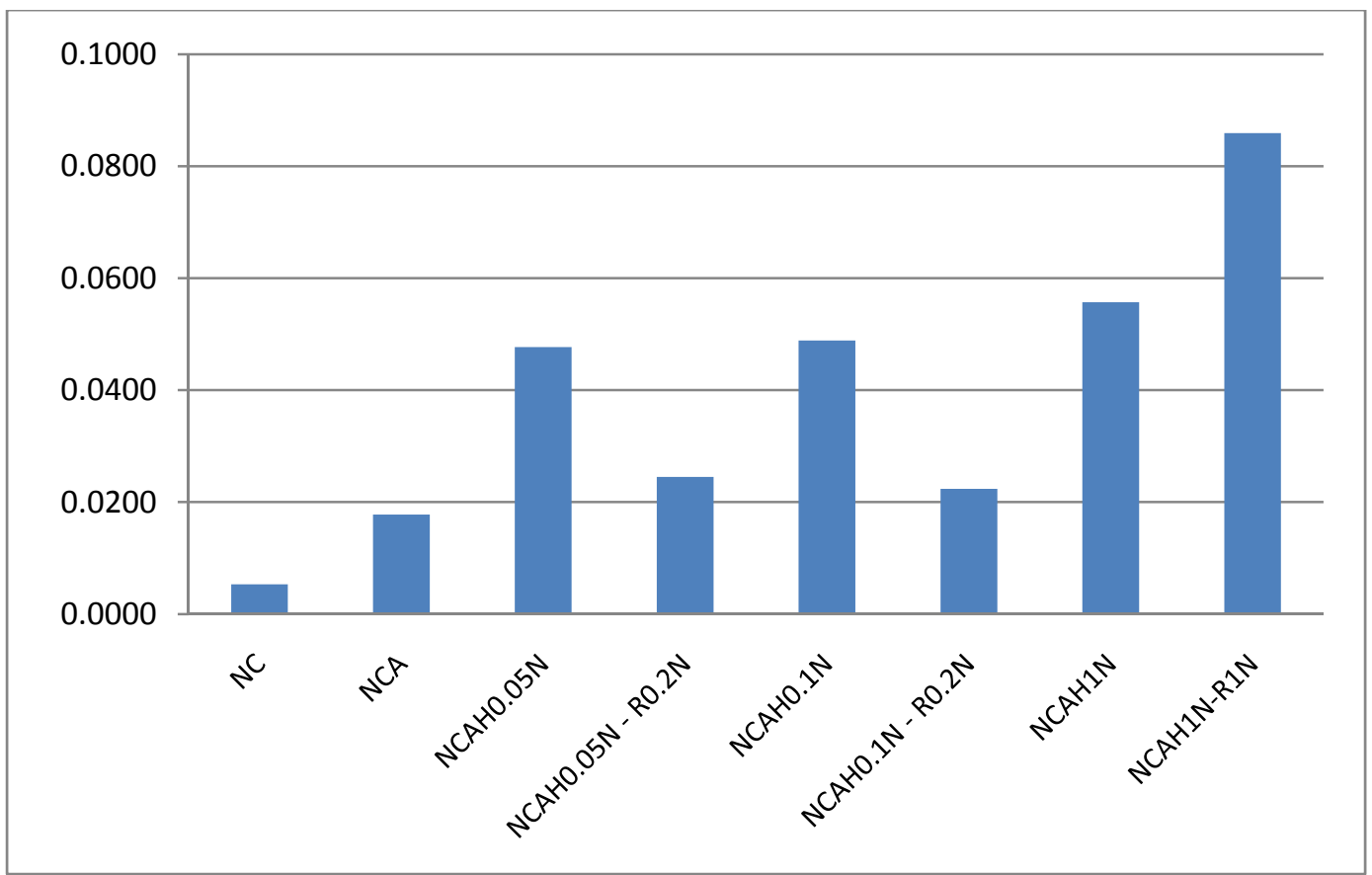

Figure 8: Rate Constants for mercury uptake by bamboo derived sorbents with skin with various treatments

\section{ACKNOWLEDGEMENTS}

This research was made possible with support, in part from the Illinois Department of Commerce and Economic Opportunity through the Office of Coal Development and the Illinois Clean Coal Institute (Grant No. ICCI 07-1).

\section{REFERENCES}

1. EPA Mercury Home, online: http://epa.gov/mercury/ [August $5^{\text {th }}$ 2010]

2. Jones, A., Hoffman, J., Smith, D., Feeley III, T., and Murphy. J., 2007, “DOE/NETL's Phase II Mercury Control Technology Field Testing Program: Preliminary Economic Analysis of Activated Carbon Injection.” Environ. Sci. Technol., Vol. 41, Issue 4, pp. 1365-1371.

3. His, H., Chen, S., Rostam-Abadi, M., Rood, M., Richardson, C., Carey, T., and Chang, R., 1998, "Preparation and Evaluation of Coal-Derived Activated Carbons for Removal of Mercury Vapor from Simulated Coal Combustion Flue Gases", Energy \& Fuels, Vol. 12, Issue 6, pp. 1061-1070

4. Bustard, J., Durham, M., Starnes, T., Lindsey, C., Martin, C., Schlager, R., and Baldrey K, 2004, "Full-Scale evaluation of sorbent injection for mercury control on coal-fired power plants", Fuel Proces. Technol. Vol. 85, Issue 6-7, pp. 549-562 
5. Li, Z., Sun, X., Luo, J., Hwang J., and Crittenden J., 2002, "Unburned Carbon from Fly Ash for Mercury Adsorption: II. Adsorption Isotherms and Mechanisms", Journal of Minerals \& Materials Characterization \& Engineering, Vol. 1, No. 2, pp. 79-96

6. Luo, J., Hein, A., and Hwang, J., 2004 "Adsorption of Vapor Phase Mercury on Various Carbons", Journal of Minerals \& Materials Characterization \& Engineering, Vol. 3, No. 1, pp. 13-22

7. Hameed, B., Din, A., and Ahmad, A., 2007, "Adsorption of methylene blue onto bamboobased activated carbon: Kinetics and equilibrium studies", Journal of Hazardous Materials, Vol. 141, Issue 3, pp. 819-825

8. Wu, F., Tseng, R., and Juang, R., 1999, "Preparation of activated carbons from bamboo and their adsorption abilities for dyes and phenols", J. Environ. Sci. Health, Vol. A34, Issue 9, pp. 1753-1775.

9. Granite, E., Pennline, H., Hargis, R., 2000, "Novel Sorbents for Mercury Removal from Flue Gas", Ind. Eng. Chem. Res., Vol. 39, Issue 4, pp. 1020-1029.

10. Mui, E., Cheung, W., Lee, V., and McKay, G., 2008, "Kinetic Study on Bamboo Pyrolysis", Ind. Eng. Chem. Res., Vol. 47, Issue 15, pp. 5710-5722 .

11. Scurlock, J., Dayton, D., and Hames, B., 2000, "Bamboo: an overlooked biomass resource", Biomass \& Bioenergy, Vol. 19, Issue 4, pp. 229- 244.

12. Asada, T., Ishihara, S., Yamane, T., Toba, A., Yamada, A., Oikawa, K., 2002, "Science of Bamboo Charcoal : Study on Carbonizing Temperature of Bamboo Charcoal and Removal Capability of Harmful Gases", Journal of Health Science, Vol. 48, Issue 6, pp. 473-479.

13. Ghorishi, S., Keeney, R., Serre, S., and Gullett, B., 2002, "Development of a Cl-Impregnated Activated Carbon for Entrained-Flow Capture of Elemental Mercury”, Environ. Sci. Technol., Vol. 36, Issue 20, pp. 4454-4459.

14. Ghorishi, S. B.; Gullett, B. K., 1997, "Fixed-bed control of mercury; role of acid gases and a comparison between carbon-based, calcium-based, and coal fly ash sorbents", Presented at the 1st EPRI-DOE/EPA Combined Utility Air Pollutant Control Symposium, Washington, DC.

15. Qu, Z., Yan, N., Liu, P., Chi, Y., and Jia, J., 2009, "Bromine Chloride as an Oxidant to Improve Elemental Mercury Removal from Coal-Fired Flue Gas”, Environ. Sci. Technol., Vol. 43, Issue 22, pp. 8610-8615.

16. Luo, J., Hwang, J., Greenlung, B., Sun, X., and Xu, Z., 2004, "Adsorption of $\mathrm{Hg}^{0}$ on the Unburned Carbon with HF Acid Leaching", Journal of Minerals \& Materials Characterization \& Engineering, Vol. 3, No. 1, pp. 41-51

17. Liu, W., Vidic R., and Brown, T., 2000, "Impact of flue conditions on Mercury uptake by Sulfur-Impregnated Activated Carbon, Environ. Sci. Technol.”, Vol. 34, Issue 1, pp. 154-159.

18. Moreno-Castilla, C., Carrasco-Marin, F., Maldonado-Hodar F., Riviera-Utrilla, J., 1998, "Effects of Non-Oxidant and Oxidant Acid Treatments on the Surface Properties of an Activated Carbon with Very Low Ash Content", Carbon, 36, Issue 1-2, pp. 145-151. 
19. Asada, T., Ohkubo, T., Kawata, K., and Oikawa, K., 2006, “Ammonia Adsorption on Bamboo Charcoal with Acid Treatment”, Journal of Health Science, Vol. 52, Issue 5, pp. 585-589.

20. Igwe, J., Abia, A., and Ibeh, C., 2008, “Adsorption kinetics and intraparticulate diffusivities of $\mathrm{Hg}$, $\mathrm{As}$ and $\mathrm{Pb}$ ions on unmodified and thiolated coconut fiber", Int. J. Environ. Sci. Tech., Vol. 5, Issue 1, pp. 83-92.

21. Ho, Y., 2006, "Second order kinetic model for the sorption of cadmium ions onto tree fern: A comparison of linear and non-linear methods", Water Research, Vol. 40, Issue 1, pp. 119125. 